\title{
Seismic risk of three main health facilities in Mexico City, Mexico
}

\author{
S. Morán-Rodríguez ${ }^{1} \&$ D. A. Novelo-Casanova ${ }^{2}$ \\ ${ }^{1}$ Posgrado en Ciencias de la Tierra, Instituto de Geofisica, \\ Universidad Nacional Autónoma de México, Mexico \\ ${ }^{2}$ Departamento de Sismología, Instituto de Geofisica, \\ Universidad Nacional Autónoma de México, Mexico
}

\begin{abstract}
We estimated the level of risk to seismic hazards of the Cardiology Hospital of the National Medical Center "Siglo XXI", the Children's Hospital "Dr. Federico Gómez" and the "Hospital de Jesus" in Mexico City, Mexico. Vulnerability of these installations was measured using optimal theoretical vulnerability indicators. Our results indicate that the main elements that increase structural risk are the lack of enough separation among the hospital's buildings generating a pounding effect in case of a local earthquake. Another factor is the use of bridges to connect buildings. Also, the type and age of construction as well as heavy objects or architectural elements placed on the roofs of the buildings not considered in the original structural design. Regarding the non-structural risk, the main problems are the use of building materials not appropriated for hospitals such as heavy panels in ceilings and large windows without protection to prevent breaking. The main elements identified that increase the functional vulnerability are the lack of special rooms for care of patients in shock. Another factor is the lack of emergency exits and stairs. The high social-administrative risk is caused by the lack of a response and/or a mitigation plan. It is possible to reduce risk of these three hospitals with low cost mitigation measures such as development and implementation of an operational emergency plan, providing regular structural maintenance to buildings, removing heavy installations from the roofs of the structures, installing locks in the medical devices and equipment as well as adopting structural seismic-resistant measures.

Keywords: health facilities, structural risk, non-structural risk, functional risk, social-administrative risk, seismic hazard, seismic risk, Mexico City, Mexico.
\end{abstract}




\section{Introduction}

Mexico City is considered one of the largest cities in the world and its urban development is complex including its health infrastructure. Morán-Rodríguez and Novelo-Casanova [1] determined that about $70 \%$ of the main hospitals in Mexico City has a level of exposure to seismic hazards between moderate and high. The other $30 \%$ although has a low level of exposure, the level of damage during a large earthquake will depend on their vulnerability conditions. Thus, it is important to identify those elements that have a high probability of being impacted by an earthquake posing a threat to life and the operability of the hospital. If possible damage is previously identified, actions can be prioritized to protect the lives of physicians, patients and workers and the operability of the installations. Although at present there are different methodologies to estimate the level of seismic exposure of hospitals [2-4], none of them provide the level of risk of a specific health facility.

The proper operation of hospitals during a seismic emergency depends significantly on the adequate operation of the overall health infrastructure system [5]. These facilities are required to operate efficiently to deal with a significant number of injured people in a short period of time. If a health facility is seriously damaged, it cannot fulfill its function when most is needed [6]. In this case, hospitals become a casualty of the disaster.

Hospitals rely on the community's infrastructure systems to operate properly such as water, electricity and transportation. This was the case of the disaster caused in New Orleans, USA, by floods of the Hurricane Katrina in August, 2005 , when health care facilities were evacuated because it was impossible to operate the power generators located in the lower levels of the hospitals and delivery of medical resources was delayed as a result of flooding of the road network $[7,8]$. Such crisis situations reinforce the need for the development of preparedness strategies to manage demands during disaster events considering the minimum level of operability required for the local infrastructure systems linked to health care facilities. When a critical infrastructure fails due to a natural phenomenon or man-made actions, the consequences are not restricted to the infrastructure itself. There might be significant consequences to other systems connected to the damaged infrastructure. Hence, the evaluation of the consequences of a failure should include not only the direct effects, but also the possible consequences to interconnected systems $[9,10]$.

Risk is considered as the estimated impact that a hazard event would have on people, services, facilities, structures and assets in a community and it is defined by the following expression [11]:

$$
\text { Risk }=\text { Hazard * Elements Exposed * Vulnerability }
$$

In this work, we extend the quantitative model developed by MoránRodríguez and Novelo-Casanova [1] to assess the risk to seismic hazards of the Cardiology Hospital of the National Medical Center "Siglo XXI" $(\mathrm{CaH})$, the Children's Hospital "Dr. Federico Gómez" $(\mathrm{ChH})$ and the "Hospital de Jesus" (JeH) in Mexico City, Mexico. In addition to damage to life, we also analyze the 
expected damage to the operation, and optimal functionality in disaster situations of these hospitals as well as their dependence to the local external infrastructure system.

\section{Method}

As pointed out above, recently, Morán-Rodríguez and Novelo-Casanova [1] developed a methodology to estimate the structural, non-structural, functional, and social-administrative vulnerabilities of health facilities in Mexico City. In this work, we extend this methodology to determine risk as well as to identify those actions needed for proper operation of these installations in disaster situations. We also analyze the interrelations of the studied hospitals with the external infrastructure systems that increase their risk.

Morán-Rodríguez and Novelo-Casanova [1] concluded that JeH is the most vulnerable of the three cases of study with a very-high level of vulnerability in the non-structural, social-administrative and structural elements. The $\mathrm{ChH}$ has very-high structural vulnerability. In the operational and the non-structural elements, this hospital has high level of vulnerability. In general, $\mathrm{CaH}$ was identified with the lowest level of structural vulnerability, however, the operational and the social-administrative elements were measured with high vulnerability. Based on these results, in this work we considered the following steps to determine seismic risk in the studied hospitals.

\subsection{Step 1: classification of damage}

Damage is classified according to Morán-Rodríguez and Novelo-Casanova [1]: $\mathrm{DL}=$ damage to life; $\mathrm{DF}=$ damage that limits the operability of the hospital; DO $=$ damage that inhibits the optimal operation of the hospital.

\subsection{Step 2: classification of causes that generate risk}

The causes that generate risk were classified as follows: (1) C1: lack of enforcement of local regulations for disaster prevention and mitigation or ignorance of the problem; (2) C2: socio-organizational factors that increase risk; and (3) C3: insufficient financial resources for disaster prevention actions.

\subsection{Step 3: identification of solutions to reduce risk}

Possible low-cost solutions to reduce risk are considered. Three categories of possible solutions are taken into account: (1) S1: replacement or removal of elements on risk; (2) S2: guarantee proper function of elements on risk; (3) S3: incorporate the necessary elements for disaster prevention and reduction.

\subsection{Step 4: assessment of risk due to dependence on external supplies and infrastructure}

In this step we analyze those supplies and infrastructure services needed for the proper operation of the health facility after a disaster situation. The hospital must 
have all kinds of medical supplies to maintain a period of autonomy for operation during at least 3-5 days. Other elements considered are: laundry services, electricity, water, and fuel and gas supplies. Also, the possible relationship with others nearby hospitals to manage injured and sick people are analyzed.

\subsection{Step 5: report preparation and presentation of results to hospital's authorities}

As a last step, a report is prepared including the identification and classification of causes and proposed solutions to reduce risk, the level of seismic exposure, the results of the analysis of risk due to the dependence on external supplies, and period of autonomy after a disaster strikes.

\section{Results}

The three hospitals selected for this study are located on the lakebed zone of Mexico City [12]. This area has high water content and exhibits a huge amplification of ground motion $[1,13]$.

Henceforth, reported percentages are estimated from the average of all possible damages from all problems detected in DL, DF, and DO, causes that generate those problems expressed in $\mathrm{C} 1, \mathrm{C} 2$, and $\mathrm{C} 3$, and proposed solutions provided in $\mathrm{S} 1, \mathrm{~S} 2$, and $\mathrm{S} 3$, respectively. For instance, $\mathrm{C} 1=62 \%$ for the nonstructural risk of $\mathrm{ChH}$ (see below) was estimated considering that the number of causes that generate those identified problems are: $\mathrm{C} 1=43, \mathrm{C} 2=14, \mathrm{C} 3=12$. Total problems: 69 . Thus, $\mathrm{C} 1=43 / 69=62 \%$.

\subsection{The Children's Hospital (ChH)}

The high level of structural vulnerability of $\mathrm{ChH}[1,14]$ is mainly because the buildings of this health facility are more than 70 years old and their characteristics of construction do not incorporate earthquake resistanttechnology. Besides, the "Mundet" building, the laundry, and machinery installations have a high probability to be seriously damaged in case of being impacted by a large earthquake due to their architectural $\mathrm{H}$ and large rectangles shapes (fig. 1), the lack of regular maintenance as well as the geological setting where these buildings are located. Overall, the structural problems identified in this hospital represent a very high level of damage to life (DL=75\%) (fig. 2(a)). However, functionality in $\mathrm{ChH}$ will be slightly impacted ( $\mathrm{DF}=14 \%$ ) (fig. 2(a)). Some of the problems identified are oxidized cracks greater than $3 \mathrm{~mm}$ in some buildings, detachment of large and heavy exterior finishes and parapets, and bridge connections between buildings that increase their risk. Although damage to optimal operability is low $(\mathrm{DO}=11 \%)$ (fig. $2(\mathrm{a})$ ), the main problems identified are the lack of regular maintenance of the hospital's buildings, water filtration in walls and ceilings, detachment of paint and plastered walls.

The main reasons for the very high level of structural risk are the lack of appropriate internal regulations for disaster prevention $(\mathrm{C} 1=46 \%)$ and the lack of sufficient economical resources for preventive actions such as the 
installation of earthquake-resistant technology (C3=39\%) (fig. 2(a)). Regarding the socio-organizational factors that increase structural risk, we identified the lack of risk prevention actions $(\mathrm{C} 2=15 \%)$ (fig. 2(a)). The proposed solutions for reducing the risk of $\mathrm{ChH}$ are: 1) Reconstruct the laundry and machinery buildings and remove heavy objects from their roofs such as machines and heavy water containers; 2) Remove all pieces of the pipeline installation and the machinery that is not currently used $(\mathrm{S} 1=38 \%)$; 3) Incorporate earthquakeresistant technology to guarantee the stability of the buildings ( $\mathrm{S} 3=34 \%$ ); 4) Provide maintenance to finishes to prevent falling; 5) Waterproof walls and ceilings (S2=28\%) (fig. 2(a)).

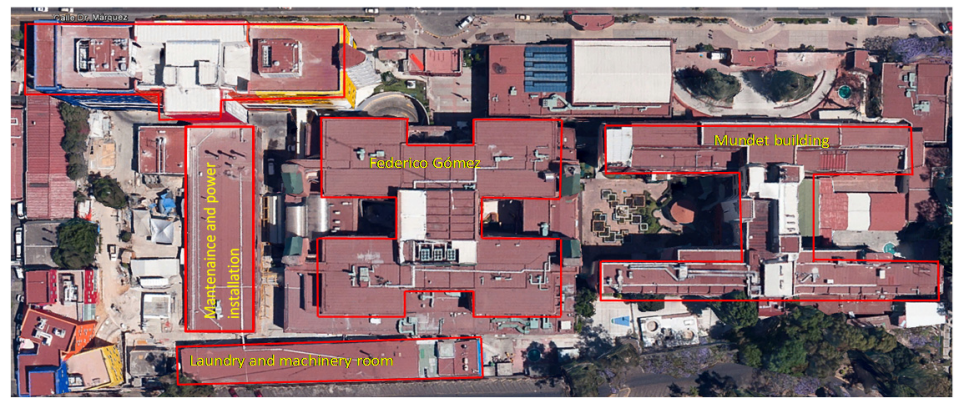

Figure 1: Architectural shape with probability of very high damage to $\mathrm{ChH}$.

Risk due to non-structural vulnerability is associated to functional aspects $(\mathrm{DF}=34 \%)$ followed by damage to life $(\mathrm{DL}=33 \%)$ and $(\mathrm{DO}=33 \%)$ (fig. 2(b)). The main problems found are: 1) Fire and explosion are possible due to spill of dangerous substances; 2) Heavy panels in ceilings and large windows with glass surfaces without protection to prevent breaking are inappropriate; 3) The emergency plan is not adequate for the three medical work shifts; 4) Incomplete installations and equipment necessary to provide medical care to patients in areas $\mathrm{A}$ and $\mathrm{B}[1]$; 5) Lack of emergency installation and equipment (e.g., fire installation, seismic alert, etc.) One of the main causes of the high non-structural risk is that local authorities are not aware of the hospital's seismic risk not even of its factors that increase this risk $(\mathrm{C} 1=62 \%)$ (fig. 2(b)). Some parts of its installations and equipment are out of order and need to be replaced or fixed $(\mathrm{C} 2=20 \%$ ) (fig. 2(b)). Also, up to present, not enough economic resources are available for risk reduction measures $(\mathrm{C} 3=18 \%)$ (fig. 2(b)). Some proposed solutions to reduce ChH's non-structural risk are: 1) Obsolete equipment and material must be removed $(\mathrm{S} 1=13 \%) ; 2$ ) It is necessary to exchange needed heavy materials placed on the roofs of the installations and finishes by lightweight materials as well to replace old equipment and installations (e.g., energy generators, elevators machines, washing machine) by new ones that provide proper function $(\mathrm{S} 2=23 \%) ; 3)$ it is necessary to place emergency equipment, flexible joints in piping installations and use brackets on shelves and furniture to avoid downfall objects during a large earthquake ( $\mathrm{S} 3=64 \%$ ) (fig. 2(b)). 


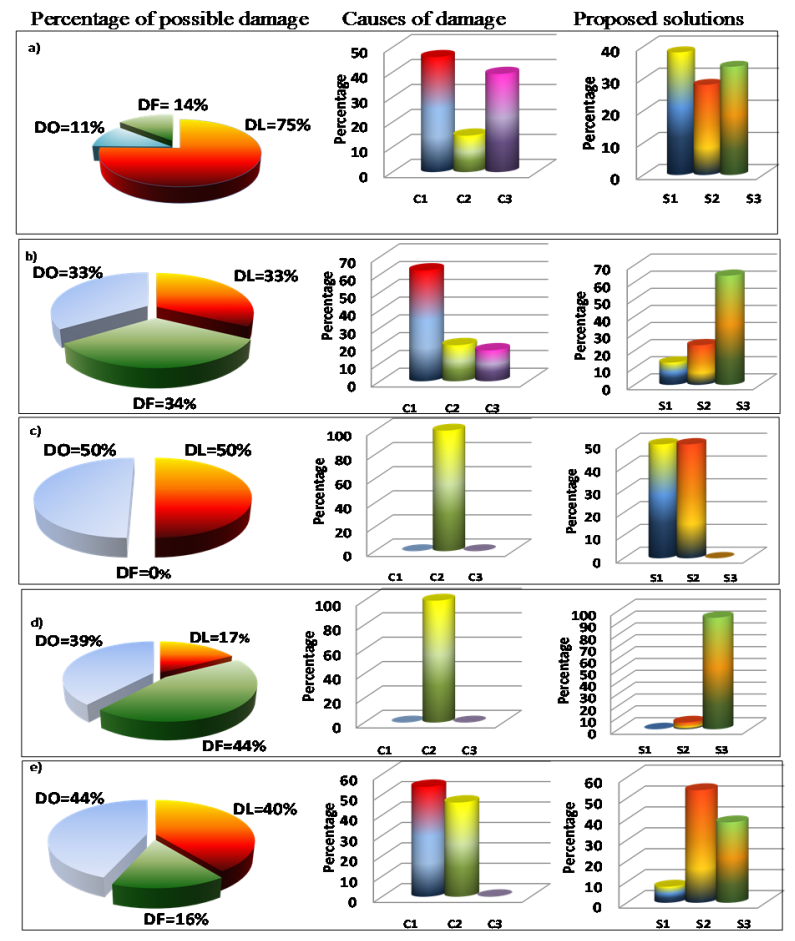

Figure 2: Risk of ChH. (a) Structural; (b) Non-structural; (c) Functional; (d) Social-administrative; (e) External supplies. DL ( $\square)=$ Damage to life; DF $(\square)$ = Damage that limits the operability of the hospital; DO $(\square)=$ Damage that inhibits the optimal operation; $\mathrm{C} 1=$ Lack of enforcement of regulations or ignorance of the problem; $\mathrm{C} 2=$ Socioorganizational factors; $\mathrm{C} 3=$ Insufficient financial resources for disaster prevention and mitigation; S1: Replacement or removal of elements on risk; S2: Guarantee proper function of elements on risk; S3: Incorporate necessary elements.

The functional element has a high level of vulnerability and risk [1, 14]. In this case, $\mathrm{DL}=50 \%, \mathrm{DO}=50 \%$, and $\mathrm{DF}=0 \%$, (fig. 2(c)). The main problems identified are: 1) Lack of special rooms for patients in shock; 2) Lack of emergency exits and stairs; 3) The security and triage areas are not delimited;4) Heavy equipment and water tanks placed on rooftops of some of its installations. The main cause of damage is because hospital's authorities are not aware of these problems and thus, actions to reduce risk is very limited $(\mathrm{C} 1=0 \%$, $\mathrm{C} 2=100 \%, \mathrm{C} 3=0 \%$ ) (fig. 2(c)). The main solutions recommended are $(\mathrm{S} 1=50 \%$, $\mathrm{S} 2=50 \%, \mathrm{~S} 3=0 \%$ ) (fig. 2(c)): 1) To provide areas A and B [1] with appropriate equipment and installations; 2) Install emergency exits and stairs; 3) Establish security and triage areas. 
The social-administrative parameter in $\mathrm{ChH}$ has a moderate level of vulnerability $[1,14]$. This condition represents high risk to the operation of the hospital $(\mathrm{DF}=44 \%, \mathrm{DO}=39 \%, \mathrm{DL}=17 \%$ ) (fig. 2(d)). The main problems found are: 1) The emergency response plan was developed only for the morning and afternoon's medical staff, do not include the night staff; 2) The list of staff and service providers is incomplete; 3) Blueprints of buildings are outdated; 4) Medical Staff is untrained on the use of triage cards to classify injured people during an emergency. As in the functional case, the main cause of these problems is that hospital's authorities are not aware of their problems $(\mathrm{C} 1=0 \%$, $\mathrm{C} 2=100 \%, \mathrm{C} 3=0 \%$ ) (fig. 2(d)). Probable solutions are: (S1=0\%, S2 $=6 \%$, S3 $=94 \%$ ) (fig. 2(d)): 1) Provide equipment (air conditioning, environment purifiers, oxygen and suction of liquids) and furniture for optimal medical care in areas A and B [1]; 2) Prepare a list of available medical personnel and of supplies companies in case of emergencies and disasters; 3) Update plans and provide staff training for patient care in case of disaster situations.

The dependence of external supplies has a high level of risk to life ( $D L=40 \%$, $\mathrm{DF}=16 \%, \mathrm{DO}=44 \%$ ) (fig. 2(e)). Some problems are: 1) Lack of autonomy to maintain operating the hospital during $72 \mathrm{hr}$ without external supplies; 2) Small temporary food shops operating in the surroundings of the hospital with inappropriate gas installations; 3) The heliport is not operating; 4) Lack of hydrants or emergency equipment in outdoor areas; 5) Lack of knowledge about nearby hospital's services during disasters; 6) The main access routes to the hospital may be seriously damaged in case of a major earthquake. The main causes of these problems are $(\mathrm{C} 1=54 \%, \mathrm{C} 2=46 \%, \mathrm{C} 3=0 \%)$ fig. 2(e)): 1) Hospital authorities are ignorant about these problems and for this reason no action has been implemented to reduce their risk; 2) The current emergency plan does not include the analysis of external supplies; 3) Insufficient resources for developing risk mitigation measures. The main solutions are $(\mathrm{S} 1=8 \%, \mathrm{~S} 2=54 \%, \mathrm{~S} 3=38 \%)$ (fig. 2(e)): 1) To implement actions to ensure external supplies for at least 72 hours after a disaster strikes; 2) Hydrants and emergency equipment should be placed in areas and corridors according to hospital's regulations; 3) Temporary food shops must be removed from the surroundings of the hospital; 4) It is necessary to establish coordination actions with nearby hospitals to optimize medical care and resources on disaster situations; 5) It is necessary to prepare alternate routes for the arrival of ambulances and injured.

\subsection{The Hospital de Jesus (JeH)}

The identified high structural vulnerability of $\mathrm{JeH}[1,14]$ is mainly due to the structural characteristics of buildings and their architectural shape. The contemporary buildings (20 de Noviembre, Pino Suarez, and Mesones) have a very high probability of damage $(\mathrm{DL}=89 \%, \mathrm{DF}=7 \%, \mathrm{DO}=4 \%$ ) (fig. 3(a)). Thus, there is a high possibility of collapse of these buildings in case of a major earthquake. The main problems found are: 1) The elongated rectangle shape of some of its installations; 2) The height difference between contiguous buildings; 3) The lack of proper separation between neighboring installations (fig. 4);

4) Detachment of large and heavy exterior finishes and parapets. The main cause 
of these problems is that this hospital lacks of a detailed structural risk assessment $(\mathrm{C} 1=56 \%)$. Thus, local authorities ignore the high seismic risk to which their installations are exposed $(C 2=29 \%)$. Finally, investment for implementation of earthquake-resistant technology is needed $(\mathrm{C} 3=15 \%)$ (fig. 3(a)). The proposed solutions are ( $\mathrm{S} 1=18 \%, \mathrm{~S} 2=42 \%, \mathrm{~S} 3=41 \%$ ) (fig. 3(a)): 1) Re-structure the construction system incorporating earthquake-resistant technology to guarantee the stability of buildings; 2) Replace heavy finishes in frontage and interiors of buildings by lighter material; 3) Provide adequate and regular maintenance to the structure; 4) Remove heavy objects from the roofs.

The non-structural vulnerability in JeH is very high $[1,14]$ and it has high impact to the operation of the installations as well as patients and medical staff's life $(\mathrm{DL}=28 \%, \mathrm{DF}=37 \%, \mathrm{DO}=35 \%$ ) (fig. 3(b)). Most problems identified are similar to those found at $\mathrm{ChH}$. Some additional ones are: 1) Overload of power contacts; 2) Large objects blocking evacuation routes; 3) Areas conditioned for triage and care of patients in disaster situation lack of all necessary equipment. The main causes identified are $(\mathrm{C} 1=66 \%, \mathrm{C} 2=18 \%, \mathrm{C} 3=16 \%)$ (fig. 3(b)): 1) Hospital's authorities are unaware of the level of seismic risk that the facility is exposed; 2) Lack of sufficient resources for risk prevention projects; 3) Lack of seismic shock-absorber for heavy equipment. Some of the solutions identified are $(\mathrm{S} 1=6 \%, \mathrm{~S} 2=27 \%, \mathrm{~S} 3=67 \%$ ) (fig. 3(b)): 1) Not to overload power contacts (they can cause fires); 2) Remove any object that is obstructing circulation and evacuation routes; 3) Provide resources for seismic prevention actions.

The functional parameter has a high level of vulnerability and risk $[1,14]$ $(\mathrm{DL}=23 \%, \mathrm{DF}=23 \%, \mathrm{DO}=54$ ) (fig. $3(\mathrm{c})$ ). In addition to similar problems to those found for $\mathrm{ChH}$, we identified: 1) That the pipeline and machinery installations are highly deteriorated; 2) Lack of proper signals for evacuation routes and hazardous materials; 3 ) Inappropriate access for disabled patients. The main causes for these conditions are $(\mathrm{C} 1=46 \%, \mathrm{C} 2=54 \%, \mathrm{C} 3=0 \%)$ (fig. 3(c)): 1) Lack of guidelines to maintain safety in this hospital; 2) Lack of knowledge of hospital's authorities about the level of seismic risk to which the hospital is exposed; 3) Lack of resources for building maintenance. Proposed solutions are $(\mathrm{S} 1=23 \%, \mathrm{~S} 2=31 \%, \mathrm{~S} 3=46 \%$ ) (fig. 3(c)): 1) Provide regular maintenance to installations and equipment; 2) Guarantee proper operation of areas A and B of the hospital [1]; 3) Design appropriate evacuation routes and security areas.

The socio-administrative element has a very-high level of vulnerability and risk $[1,14](\mathrm{DL}=44 \%, \mathrm{DF}=32 \%, \mathrm{DO}=24 \%)$ (fig. 3(d)). The problems found here are: 1) Hospital authorities do not prioritize assessment of risk and implementation of mitigation and prevention actions; 2) Lack of a complete and operational emergency response plan; 3) Lack of investment to determine the level of risk that they are exposed. The main cause $(\mathrm{C} 1=0 \%, \mathrm{C} 2=100 \%$, $\mathrm{C} 3=0 \%$ ) is that hospital's authorities do not know the level of seismic risk that they are exposed. Probable solutions are (S1=0\%, S2=23\%, S3=78\%) (fig. 3(d)): 1) Hospital's authorities need to be trained on disaster management issues;

2) Updating the emergency response plan; 3) Resources need to be invested to mitigate the seismic risk of the health facility. 


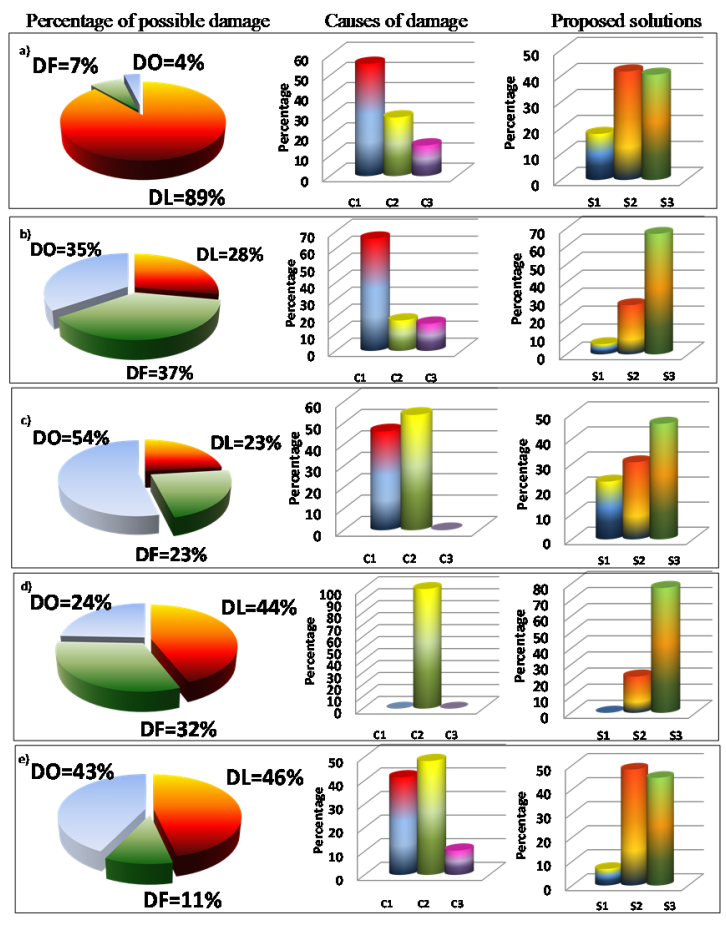

Figure 3: Risk of JeH. (a) Structural; (b) Non-structural; (c) Functional; (d) Social-administrative; (e) External supplies. (For symbology see fig. 2.)

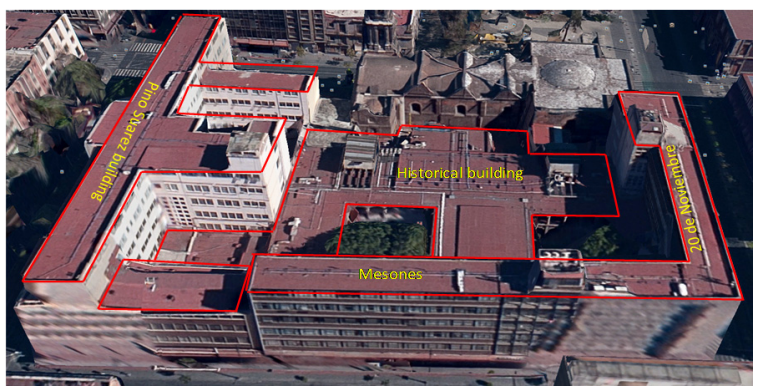

Figure 4: Architectural shape with probability of very high damage to JeH.

The main problems related to external supplies are similar to those found at $\mathrm{ChH}(\mathrm{DL}=46 \%, \mathrm{DF}=11 \%, \mathrm{DO}=43 \%)$ (fig. 3(e)). In addition, the period of autonomy of JeH needs to be analyzed as well as the availability of medical supplies providers after a disaster strikes. The main causes of these problems are due to the fact that hospital's authorities are not aware of the high seismic risk to which they are exposed and the lack of resources for assessment of risk $(\mathrm{C} 1=41 \%, \mathrm{C} 2=49 \%, \mathrm{C} 3=10 \%)$ (fig. 3(e)). In addition to those solution provided to $\mathrm{ChH}$, we found that $(\mathrm{S} 1=7 \%, \mathrm{~S} 2=48 \%, \mathrm{~S} 3=45 \%)$ (fig. 3(e)): 1) Hospital's 
authorities must be trained to perform mitigation measures to guarantee the safety and operation of the installations; 2) It is necessary to analyze alternative roads for the arrival of injured people during disasters.

\subsection{The Cardiology Hospital (CaH)}

The CaH's seismic risk is similar to that of the other two analyzed hospitals. Here, we only present a summary of the main results. This hospital suffered serious damage during the 1985 Michoacan earthquake [15]. As a consequence, all buildings that did not collapsed, were reinforced with earthquake resistanttechnology. For this reason, the structural vulnerability of this hospital is between moderate and low $[1,14]$. However, we identified DL, DO and DF type of damages. This is because the problems observed are in areas of the hospital that provide life support to patients (e.g. surgery rooms, intensive care, and laboratories). The non-structural parameter has very-high level of vulnerability and risk [1, 14]. Some problems found are: 1) It is likely that heavy panels in ceilings, large windows, furniture, shelves with medications, and other objects will fall during an earthquake; 2) It is necessary to reduce seismic risk to protect life of patients and medical staff as well as the operation of the installations in case of emergencies. The functional parameter was identified with high level of vulnerability and risk [1, 14]. The main problems here found are: 1) There are objects obstructing evacuation routes; 2) Some emergency exits are closed. We recommend delimitating areas of triage and those specially prepared for new patients after a disaster. In the social-administrative element, risk is high $[1,14]$. $\mathrm{CaH}$ requires using the existing emergency plan and make it fully operational. Also, this hospital needs to strength its capacity for autonomy during a disaster.

\section{Discussion}

In general, the level of structural risk of the three studied hospitals is very high with also a high probability of causing great damage to life and the operability of the health facility. The main problems for those buildings built before the 1985 earthquake in Mexico City [15] are: 1) The use of very complex architectural shapes; 2) The absence of seismic-resistant technology; 3) Buildings with more than four floors; 4) Lack of regular maintenance; 5) Small separation between adjacent buildings; 6) Overload of the structural system that were not considered in the original building design. Hospital's buildings constructed after the 1985 earthquake followed the new construction regulations. However, their main problems are: 1) Use of complex architectural shapes; 2) Use of bridges to connect buildings; 3) Buildings with more than four floors.

In general, the very high risk in the non-structural element is due to the use of inappropriate materials for construction. It is necessary to lock furniture and equipment to prevent their fall during an earthquake. Also, it is important to implement security measures such as installing emergency material and equipment as well as fire protection systems and seismic alerts. The high functional vulnerability is due to the lack of rooms in areas A and B [1] to support life of patients in shock, absence of triage areas, the lack of 
decontamination areas in operating rooms and intensive care sites. It is necessary for the analyzed hospitals to have an operational and updated emergency plan, delimit security and triage areas, and to provide training to medical staff on disaster response management. The social-administrative vulnerability is high because of the need of sufficient financial resources for disaster prevention actions. It is necessary an assessment of the supplies required for a proper autonomous operation of health facilities during at least 72 hours after a disaster strikes. From the combined results of Morán-Rodriguez and Novelo-Casanova $[1,12]$ and those obtained here, we can consider that the health infrastructure of Mexico City has a high level of seismic risk. Thus, it is necessary to assess in detail the level of vulnerability and risk of each main hospital in this city.

\section{Conclusions}

To reduce the structural vulnerability of the three studied hospitals: 1) Buildings should not be built using complex architectural designs; 2) It is necessary to incorporate seismic-resistant technology to their installations; 3) Provide regular and proper maintenance to buildings. Non-structural and functional vulnerabilities can be reduced by low-cost measures: 1) Prevent spillover of hazardous substances; 2) Lock all furniture and medical equipment that may fall in case of an earthquake. Regarding the social-administrative vulnerability, it is necessary to implement and/or update operational emergencies plans, including the analysis of external supplies and the relationship with other health facilities to insure medical assistance to patients during a disaster. Damage to $\mathrm{JeH}$ and $\mathrm{ChH}$ represents high risk to life and the operation of their installations. It is important investment to develop preventive and response actions. We encourage Mexico City's civil protection authorities to establish a program and enforce regulations to reduce the high level of seismic risk of local health facilities.

\section{Acknowledgements}

The authors are grateful to R. Bonilla-Avila and G. Morán-Rodríguez for their field research assistance. Special thanks are due to Y. Bonilla-Moran, A. MoranBalderas, G. Rodriguez-Quiroz, and R. Bonilla-Parra for their support. Thanks are also due to M. A. Hernandez-Merino for helpful discussions. We appreciate the collaboration of authorities, medical staff, patients and workers of the Cardiology, Children, and de Jesus hospitals for providing local data.

\section{References}

[1] Morán-Rodríguez S. \& Novelo-Casanova D.A., Seismic vulnerability assessment of health facilities in Mexico City, Mexico, Proc. of the $5^{\text {th }}$ Conference on Disaster Management and Human Health Risk, pp. 115126, 2015.

[2] Secretaria de Gobernación y Sistema Nacional de Protección Civil (in Spanish), Guía Práctica del Programa Hospital Seguro, México Distrito Federal, 2008. 
[3] Flax, L. K., Jackson, R. W., \& Stein, D. N., Community vulnerability assessment tool methodology. Natural Hazards Review, 3(4), pp. 163-176, 2002.

[4] Arboleda, C., Abraham, D., Richard, J., \& Lubitz, R. Vulnerability assessment of health care facilities during disaster events. Infrastructure Systems, 15(3), pp. 149-161, 2009.

[5] Rinaldi, S. M., Modeling and simulating critical infrastructures and their interdependencies. Proc. of the 37th Hawaii Int. Conf. on System Sciences, IEEE, Piscataway, N.J., pp. 1-8, 2004.

[6] Gunn, S.W.A., Health effects of earthquakes. Disaster Prevention and Management, 4(5), pp. 6-10, 1995.

[7] Centers for Disease Control and Prevention, Public Health Response to Hurricanes Katrina and Rita - Louisiana, MMWR, 55(2), pp. 29-30, 2005. Online. http://www.cdc.gov/mmwr/pdf/wk/mm5502.pdf

[8] Centers for Disease Control and Prevention, Assessment of Health-related Needs after Hurricanes Katrina and Rita - Orleans and Jefferson Parishes, New Orleans Area, Louisiana, October 17-22, 55(2), pp. 38-41, 2005. Online http://www.cdc.gov/mmwr/pdf/wk/mm5502.pdf

[9] Lee, E. E., Mendonca, D., Mitchell, J. E., \& Wallace, W. A., Restoration of services in interdependent infrastructure systems: A network flows approach. Technical Rep. No. 38-03-507, Decision Sciences and Engineering Systems, Rensselaer Polytechnic Institute, Troy, N.Y., 2003.

[10] Wallace, W. A., Mendonca, D. M., Lee, E. E., Mitchell, J. E., \& Chow, J. H. Managing disruptions to critical interdependent infrastructures in the context of the 2001 World Trade Center attack. Beyond September 11: An account of post disaster research. Natural Hazards Research \& Applications Information Center, Public Entity Risk Institute, and Institute for Civil Infrastructure Systems, Special Publication \#39, Univ. of Colorado, Boulder, Colo, 2003.

[11] Crichton, D., The risk triangle. Natural Disaster Management, Ingleton, J., London: Tudor Rose, pp. 102-103, 1999.

[12] Morán-Rodríguez S., \& Novelo-Casanova D.A. Spatial analysis of the level of exposure to seismic hazards of health facilities in Mexico City, Mexico. Geomatics, Natural Hazards and Risk, 3(3) pp. 279-292, 2012.

[13] Ordaz, M. \& Singh, S.K., Source spectra and spectral attenuation of seismic waves from Mexican earthquakes, and evidence of amplification in the hill zone of Mexico City. Bulletin of the Seismological Society of America, 82(1) pp. 24-43, 1992.

[14] Morán-Rodríguez, S., (In Spanish), Modelo cuantitativo para la estimación de la vulnerabilidad de las instalaciones de salud ante un evento sísmico, Tesis doctoral, Universidad Nacional Autónoma de México, México D.F., p. 142, 2012.

[15] Esteva, L., The Mexico earthquake of September 19, 1985: Consequences, lessons, and impact on research and practice. Earthquake Spectra, 4(3), pp. 413-426, 1988. 